\title{
Logoterapide Kullanılan Kavramların ve Tekniklerin Türk Kültürü’nde
}

\section{Uygulanabilirliği}

Özlem TAGAY ${ }^{1}$
Aygül NALBANT ${ }^{3}$

Geliş Tarihi: 20.04 .2014

Kabul Tarihi: 15.12 .2015

\section{$\ddot{\mathbf{O z}}$}

Logoterapi, Hümanist ve Varoluşçu düşünce okulları arasında anlam üzerine odaklanan bir terapi yaklaşımıdır. Logoterapiyi geliştiren Viktor E. Frankl (1905-1997), dünya çapında ünlü Avusturyalı bir psikiyatristtir. Frankl anlamın ve değerlerin insan yaşamı üzerindeki önemini vurgulamıştır. Psikolojik danışma kuramları pek çok Avrupalı ve Amerikalı psikoloğun katkılarına dayalı olarak geliştirilmiştir. Araştırmacılar kültürün bireyler üzerindeki etkisi ile uzun süredir ilgilenmektedir ancak konu ile ilgili tutarlı çalışmalara son zamanlarda rastlanmaktadır. Bu makalede, logoterapide kullanılan kavramlar ve teknikler Türk kültürü açısından incelenmiştir. Yapılan çalışmanın sonucunda, Logoterapide kullanılan anlam istemi, varoluşsal engellenme, kolektif nevrozlar, varoluşsal boşluk, yaşamın anlamı, sevginin anlamı, acının anlamı ve süper anlam gibi bazı kavramların ve paradoksal niyet ve düşünce odağının değiştirilmesi gibi tekniklerin Türk kültüründe kullanılması açısından uygun olduğu söylenebilir.

Anahtar Sözcükler: Logoterapi, logoterapinin kavram ve teknikleri, Türk kültürü

\footnotetext{
${ }^{1}$ Yrd. Doç. Dr., Mehmet Akif Ersoy Üniversitesi, RPD Anabilim Dalı, ozlemtagay@ gmail.com

${ }^{2}$ Prof. Dr., Hacettepe Üniversitesi, RPD Anabilim Dalı, nva@ hacettepe.edu.tr

${ }^{3}$ Yrd. Doç. Dr., Bozok Üniversitesi, RPD Anabilim Dalı, aygulnalbant@yahoo.com
} 


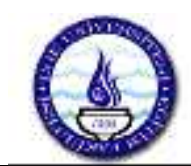

Practicality of Logotherapy Concepts and Techniques in Turkish Culture

Submitted by 20.04.2014

Accepted by 15.12.2015

\begin{abstract}
Logotherapy is a meaning-oriented approach to therapy, among humanistic and existentialist schools of thought. Victor E. Frankl, (1905-1997), the founder of logotherapy, was a distinguished Austrian psychiatrist with a world-wide reputation. Frankl emphasized the importance of meaning and value in human life. Psychological Counseling Approaches has developed by the contribution of many European and American psychologists. Researchers have been interested in the impact of culture on individuals for a very long time but more consistent study of culture on individuals has only occurred recently. In this article the concepts such as will to meaning, existential frustration, collective neurosis, existential vacuum, meaning of life, meaning of love, meaning of suffering and super meaning; techniques such as paradoxical intention and de-reflection have been investigated according to the Turkish Culture. It has seen that some concepts and techniques of logotherapy said to be suitable for using in Turkish Culture.
\end{abstract}

Key Words: Logotherapy, concepts and techniques of logotherapy, Turkish culture 


\section{Giriş}

Varoluşçu yaklaşıma göre insan seçenekler arasından seçebilen, kararlar verebilen ve bu kararlarının sorumluluğunu alabilen bir canlıdır. Viyanalı ve varoluşsal yönelimli Frankl, logoterapi sözcügüüü 1920’lerde ilk kez kullanmıştır. Daha sonra “varoluşsal analiz” terimini eşanlamlı olarak kullanmış fakat diğer varoluşçu yaklaşımlarla karışmasını engellemek için son yıllarda kendi kuramından kuramsal ya da terapötik bağlamda "logoterapi" olarak söz etmiştir (Patterson, 1973). Yahudi bir ailenin çocuğu olan Viktor Frankl 1942-1945 yılları arasında Auschwitz toplama kampında yaşamıştır. Frankl, toplama kampındaki yaşamının logoterapi üzerinde de etkileri olduğunu belirtmiştir. Frankl gelişimi süresince Freud ve Adler'den etkilenmiş fakat aynı zamanda onların bazı düşüncelerine karşı çıkmıştır (Jones, 1995).

Logoterapi psikoanaliz ile kıyaslandığında daha az geçmişe yönelik ve daha az içedönük olan bir yöntemdir. Daha çok gelecek üzerine, yani birey tarafından gelecekte gerçekleştirilebilecek anlamlar üzerine odaklaşır. Logoterapi anlam merkezli bir psikoterapidir. Logos "anlam" anlamına gelen Yunanca bir kelimedir (Jones, 1995). Hillmann (2004)'e göre logoterapi bireyler için en temel dürtünün, varoluşlarının, anlamını kavramak fikrine dayanan bir kavramdır (Sharf, 2014 ss.148). Çok az klinisyen anlamın psikoterapideki rolüne önemli katkıda bulunmuştur ve bu alana olan ilgilerini devam ettirmişlerdir. Frankl ise kariyerinin başlangıcından itibaren anlamın psikopatolojisi ve terapideki yerine odaklanmıştır (Patterson, 1973).

Alanyazında çok fazla araştırmaya rastlanmamakla birlikte, Türkiye'de de batıda geliştirilen kuramların Türk kültürüne uygulanabilirliği tartışılmaya (Bektaş, 2006; Doğan, 2005; Gültekin ve Voltan-Acar, 2004; Kağnıc1, 2013; Voltan-Acar 2004/2012 ss.102-110,) başlamıştır. Türk kültürünün genel olarak toplulukçu bir kültür olduğu söylenebilir. Kültürel farklılıkları ya da benzerlikleri ortaya koyarken kültürel sınıflamadan yararlanılır. Sıklıkla kullanılan sınıflama, bireyci ve toplulukçu kültürdür. Bireyci kültürün genellikle Batı toplumlarında, toplulukçu kültürün Doğu toplumlarında baskın olduğu ifade edilmektedir. Bireyci kültür bakış açısına sahip batılı araştırmacıların bireyci kültür bakış açısıyla yaptıkları değerlendirmeler, araştırmalar ve yorumlamalar yanlış olabilmektedir (Ergun, 1991). Kültürel farklılıklara duyarlılıkla ilişkili çalışmalar Türk alanyazında da ilgi görmeye başlamıştır. Bazı araştırmacılar Türk toplumundaki kültürel özellikleri ( mamoğlu, 1987; mamoğlu, 1998; Kağıtçıbaşı, 1987) araştırmaya ve geleneksel batı kuramlarının Türk kültürüne uygulanabilirliğini tartışmaya (Gültekin ve Voltan-Acar, 2004; Mocan-Aydın, 2000; VoltanAcar, 2004/2012 ss.102-110) başlamıştır. Türk kültürüne ilişkin farklı sonuçlar belirten her 
araştırmayla birlikte batıda geliştirilen psikolojik danışma kuramlarının Türk Kültürüne uygulanabilirliğine ilişkin sorular da artmaktadır.

Logoterapi tinsel boyut ve anlam odaklı bir teori, müdahale yaklaşımı ve felsefi sistemdir. nsan hayatında anlamın rolüne, insanın kendi değer sistemini oluşturmasına odaklanmaktadır. Hayattaki deneyimler, kaçılamayan acı ve zorluklar, anlam bulma ve yaratma özgürlüğü bireye aittir (Washburn, 1998).

Bu çalışmada özellikle yaşamda anlam üzerine odaklanmasından dolayı logoterapinin kavramlarının ve tekniklerinin Türk kültürü açısından incelenmesinin uygun olacağ düşünülmektedir. Bilindiği gibi her toplum kendi kültürel, sosyolojik özelliğini içinde taşımaktadır. Türk toplumu ile batı toplumları arasında gelenekler, kültür ve iletişim biçimleri açısından pek çok farklılık olduğu söylenebilir. Dolayısıyla batıda geliştirilen psikolojik danışma kuramları her kültür için uygun olmayabilir. Psikolojik danışma alanının gelişebilmesi için batı toplumlarında geliştirilen kuramların Türk kültürü için uygun olup olmadığını incelemek ortaya çıkabilecek yanılgıları engelleyebilir. Bu çalışmada öncelikle Logoterapinin kavramları ve teknikleri ile ilgili bilgi verilmiştir. Daha sonra da logoterapide ifade edilen kavramlar ve teknikler Türk Kültürü açısından incelenmiştir.

\section{Logoterapinin Kavramları}

Bu bölümde öncelikle Frankl'ın belirttiği anlam istemi, varoluşsal engellenme, noöjenik nevrozlar, kolektif nevrozlar, nöodinamikler, varoluşsal boşluk, yaşamın anlamı, varoluşun özü, sevginin anlamı, acının anlamı, süper anlam ve yaşamın çekiciliği kavramları anlatılmış ardından bu kavramlar Türk kültürü açısından tartışılmıştır.

\section{Anlam stemi}

nsanın anlam arayışı yaşamındaki temel bir güdüdür. Yaşamda anlam kişiye özgüdür bu nedenle eşsizdir. Anlam istemi insanın insanlığının gerçek bir dışavurumu olmasının yanı sıra ruh sağlığının da güvenilir bir ölçütüdür. Anlam ve amaç yoksunluğu duygusal uyumsuzluğun bir göstergesidir (Frankl, 1992). Anlam insanın kendisi tarafından bulunmalıdır ve temel yaşamsal sorumluklardan biridir (Sezer, 2012).

Psikolojik işlevler, içinde yaşanılan sosyal ve kültürel normlara göre adlandırılırlar. Örneğin Wig' in (1990) çalışmasına göre batı toplumlarında akıl-beden ikilemi baskınken doğu kültüründe böyle bir durum söz konusu değildir. Ayrıca doğu kültürlerinde sağlıklı birey ya da ruh sağlığı tanımlamalarında dinin etkisi de yer almaktadır. Çin kültüründe ruh sağlığından bahsedilirken çevre ve toplum sağlığından da söz edilmektedir. Batı kültüründen farklı olarak doğu kültürlerinde toplum öne çıkmaktadır (Akt; Erdur-Baker, 2007). Araştırma sonuçlarına göre daha çok toplumcu kültür özellikleri gösteren Türk toplumunun artan kentleşme ve sosyo- 
ekonomik gelişmeyle beraber son yıllarda bireyci toplum özellikleri gösterdiği belirtilmektedir (Kağıtçıbaşı, 1991). Türk Kültürü Asya'dan, Avrupa'dan, slam dininden ve Anadolu coğrafyasında yaşamış insan toplulukları ve milletlerin kültürlerinden etkilenmiş bir kültürdür.

Anlam arayışındaki kişiler niçin yaşadıklarının, yaşamının bir amacı olduğunun farkında olarak bu varoluşu sürdürmek isteyen kişilerdir. Anlam arayışı aynı zamanda bir ihtiyaçtır. Yukarıdaki açıklamalar dikkate alındığında toplumun ve dinin etkisiyle birlikte anlam isteminin Türk toplumu için oldukça önemli bir ihtiyaç olabileceği ve bu kavramın Türk kültürü açısından da anlamlı olacağı söylenebilir.

\section{Varoluşsal Engellenme}

nsanın anlam istemi engellenebilir. Bu durumda Logoterapi “varoluşsal engellenmeden” söz eder. Danışanlar artık Freud ve Adler çağındaki gibi aşağılık duygularından veya cinsel engellemelerden şikâyet etmemektedir. Danışanların psikiyatriste gitmelerinin nedeni boşluk duygularıdır, varoluşsal engellenmeleridir (Frankl, 1992).

Toplulukçu kültürleri bireyci kültürlerden ayıran temel özellik toplulukçu kültürlerde kişinin kendisini kendine yeten, bağımsız bir birey olarak değil de bir grubun (örneğin aile, kavim, ulus, vb.) parçası olarak görmesi, bunun sonucunda da bireysel amaç ve davranışlarının grubunun norm ve beklentileri ile uyumlu olmasını sağlamak kaygısıdır (Aycan ve Kanungo, 2000). Mc Whirter (1983) Türkiye'de ilişkilerin Amerika’ya göre daha hiyerarşik bir yapıda sürdürüldüğünü belirtmektedir. Küçükler saygı gereği her zaman büyüklerinin dediklerini yapmak durumundadırlar. Söylenene itiraz etmek büyüklere saygısızlıktır. Bu durum kişilerin bireyselleşmesinin önünde engel oluşturmaktadır.

Yaşamın anlamı evrensel değildir ve kişiden kişiye değişebilir. Türk toplumunun insanlarına sunduğu yaşam seçeneklerinin birer şablon olduğu söylenebilir. "Okula git", “askerliğini yap”, “evlen”, özellikle kız çocuklarına "büyüyünce gelin olacaksın” şeklindeki yönlendirmeler yaygındır (Voltan-Acar, 2004/2012 ss.103). Ayrıca meslek seçiminde de ailelerin etkisi büyüktür. Bireyler kendilerine uygun meslekleri seçmek yerine ailelerin ve çevrelerinin yönlendirmelerine uymaktadır. Bunun yanında üniversitelere giriş sistemi de öğrencilerin kendilerine uygun alanlarda eğitim almalarını engellemektedir (Kuzgun, 2000). Dolayısıyla, Türk insanının kendi yaşamına yön vermesi ve kendi yaşam anlamını seçmesi konusunda kültürel özelliklerden dolayı engellemelerle karşılaştığı söylenebilir.

\section{Nöojenik Nevrozlar}

Nöojenik nevrozlar daha çok varoluşsal sorunlardan kaynaklanmaktadır. Bu tür sorunlar arasında anlam isteminin engellenmesi büyük rol oynamaktadır. Her çatışma nevrotik değildir. Bir ölçüde çatışma normal ve sağlıklıdır. Acı çekmek her zaman için patolojik bir olgu değildir. 
Acı nevrotik bir semptomdan çok varoluşsal engellenmeden kaynaklanıyorsa insanca bir başarı da olabilir. Logoterapi yaklaşımında, insanın kendi varoluşuna anlam bulma arayışının hatta buna yönelik kuşkusunun her durumda bir hastalıktan kaynaklandığı ya da hastalığa yol açtığı görüşü reddedilmektedir. Logoterapi danışanın kendi varoluşunun gizli anlamının farkına varmasını sağlamaya çalışmıştır (Frankl, 1992).

Yukarıdaki ifadelerden de anlaşılabileceği gibi anlam arayışının engellenmesi nöojenik nevrozlara sebep olmaktadır. Türk toplumunda bireylerin öncelikli olarak fiziksel ve güvenlik ihtiyaçlarını gidermeye çalıştıklarını, dolayısıyla geçim sıkıntısını yoğun olarak yaşayan bu bireylerin günlük hayatta kendileri için uygun olmayan anlamlara yönelebilecekleri söylenebilir. Son yıllarda çok sık karşılaşılan şiddet, hırsızlık, cinsel taciz ve zorbalık durumlarının da bu nöojenik nevrozlardan kaynaklandı̆̆ı söylenebilir.

\section{Kolektif Nevrozlar}

Noöjenik nevrozların yanında Frankl modern yaşam mücadelesinde ortaya çıkan diğer rahatsızlıklardan bahsetmektedir. Bu kolektif nevroz olarak adlandırılır. Bu durum dört büyük semptomla ifade edilmiştir (Das, 1998). Bunlar; a) Belirgin olmayan gelecek mücadelesi için günden güne rutin davranışların devam etmesi, (monotonluk), b) Kişinin hayatında kontrol edemediği durumları kadere bağlaması (kadercilik), c) Grup düşüncesi içerinde bireyin kişisel sorumluluklardan vazgeçmesi (vurdumduymazlık) ve d)Grup ruhuyla beraber diğerlerinin düşünce ve davranışlarına olumsuz yorumlarda bulunulması (fanatizm). Frankl bütün bu semptomların nedenlerini insanların sorumluklarından ve özgürlüklerinden kaçma isteklerine bağlamıştır. nsanların kendilerinden kaçmalarının farklı nedenleri bulunur. Bu genel kaçma davranışlarından ve sonuçlarından bazıları şunlardır (Das,1998): a) Kişi sıkıntı verici durumlarla karşılaşır ve bu durumdan kaçmak için alkol, sigara kullanımı gibi mazoşist davranışlar sergiler, b) Kişinin boşluk duyguları sonucu, takıntılı yeme davranışları ya da göze çarpıcı şekilde madde tüketimi davranışları görülebilir, c)Kişi kendini yetersiz, engellenmiş veya utanç kaynağı olarak görebilir. Bunun sonucunda kendini manevi disiplin altına alabilir.

nsanda doğal bir eğilimin ürünü olarak kabul edilen saldırganlığın, birden fazla insan tarafından gerçekleştirilen şiddet niteliğinde bir grup davranışı olarak ortaya çıkmasında insanın doğuştan getirdiği biyolojik özellikleri kadar aile, kültür ve bunların şekillendirdiği yaşam biçimlerinin ve hayata bakış tarzlarının etkisini de göz ardı etmemek gerekir. Dolayısıyla ifade edilen tüm etkenlerin birbiri ile etkileşerek ortaya çıkardığı fanatizm ile birey ve topluluklar kendi kendilerini topluma kabul ettirme yollarını ararlar (Erkal, Baloğlu ve Baloğlu, 1997). 
Türk Toplumunun büyük bir kısmının slami görüşle yetiştirilmesi, kadere, alın yazısına, iyi ya da kötü her şeyin Allah'tan geldiğine inanılması; kişilerin sorumluluk almasını, değişimin kendi ellerinde olduğu gerçeğini kavramalarını zorlaştırmaktadır (Voltan-Acar, 2004/2012 ss.106-107). Türk kültürünün belirgin özellikleri arasında kadercilik, kanaatkârlık, az ile yetinme, geleceğe ilişkin plansızlık, başarı güdüsündeki eksiklik, yeni koşullara uyma esnekliğinde zayıflık, belirsizlikten korkma yer almaktadır. Dolayısıyla Türk insanı dinin etkisiyle kontrol edemediği olayları kadere bağlama eğilimi gösterebilmektedir. Kaderci bir tutum ve bakış açısı Türk toplumunda oldukça yaygındır (Macit, 2010). Toplumcu kültür özelliğinden dolayı da Türk insanının kişisel sorumluluklardan kaçtı̆̆ı ve vurdumduymaz özellikler gösterdiği söylenebilir. Sorumluluklardan dolayısıyla özgürlükten kaçınma eğilimleri alkol kullanımı, saldırganlık, aşırı fanatizm gibi bir takım olumsuz davranışları beraberinde getirir. Bu davranışlar da kolektif (ortak) nevroz tanımına uymaktadır.

Anlam arayışının insanlar için hayati olduğuna inanan Fabry (1988,akt; Das 1998) farklı bir bakış açısıyla anlamı şöyle belirlemiştir: a)Henüz anlam bulamamış gençler, b)Anlam sahibi olduğu halde bu anlamı kaybetmiş olanlar, c)Emeklilik, yaşlılık ve ölümle yüz yüze olanlar, d) Hayat durumları ani şekilde değiş̧enler, organ kaybı, kariyer veya eş kaybı gibi durumlara maruz kalanlar, e)Tiryakilikten ve bağımlılıktan kurtulanlar ve f) Ruhsal hastalıklardan, depresyondan ve anksiyeteden zarar görenler. Bu ihtiyaçlar bireylerin ruhsal hastalıklar yaşamasına nedendir.

Bireylerin yaşam tarzları, sorunlarının farkında olması ve sorunlarıyla başa çıkma şekilleri sosyal ve kültürel yapıdan etkilenebilmektedir (Herman, Buffardi, ve Tetrick, 2006) Örneğin ülkemizde yaşanan 1999 depreminde doğal afet sonrası yaşanan kriz, afetin kendisinden ziyade neden olduğu sosyal ilişkilerin kopmasından, güvenli ortamın güvensiz ortama dönüşmesinden, komşu ve akrabaların yitirilmesinden, düzenli ev ve iş yaşamının alt üst olmasındandır (Erdur-Baker, 2007). Türk toplumunda bireylerin hayat şekilleri değiştiğinde ya da herhangi bir kriz anında sosyal destek sisteminin daha da çok çalıştığı ve insanların birbirlerinin desteğine daha çok ihtiyaç duyduğu söylenebilir

\section{Nöodinamikler}

Kuşkusuz insanın anlam arayışı içsel denge yerine içsel gerilim yaratabilir. Ruh sağlı̆̆ının vazgeçilmez ön koşulu bu gerilimdir. Dünyada kişinin en kötü şartlarda bile yaşamını sürdürmesine, yaşamında bir anlam olduğu bilgisi kadar etkili bir şekilde yardımcı olan başka bir şey yoktur. Ruh sağlığının belli bir gerilim ölçüsüne, kişinin ulaşmış olduğu şeyle ulaşması 
gereken arasındaki gerilime dayandığı söylenebilir. Bu tür bir gerilim insanda yapısaldır ve bu nedenle ruh sağlı̆̆ında vazgeçilmezdir (Frankl, 1999).

Ruh sağlığı konusunda insanın her şeyden önce dengeye ya da psikolojideki deyişiyle "homeostasis"”e bir başka ifadeyle, gerilimsiz bir duruma ihtiyaç duyduğunu varsaymak doğru değildir. nsanın gerçekte ihtiyaç duyduğu şey, gerilimsiz bir durum değil, daha çok, uğruna çaba göstermeye değer bir hedef, özgürce seçilen bir amaç için uğraşmak ve mücadele etmektir. Kişinin ihtiyaç duyduğu şey her ne pahasına olursa olsun, gerilimi boşaltmak değil, onun tarafından yerine getirilmeyi bekleyen potansiyel bir anlamın çağrısıdır. nsanın ihtiyaç duyduğu şey homeostasis değil nöodinamiklerdir. Bu nedenle terapistler, danışanlarının ruh sağlığını güçlendirmek istedikleri takdirde, kişinin kendi yaşamının anlamı doğrultusunda yeniden yöneliş yoluyla belli ölçülerde gerilim yaratmaktan korkmamalıdır (Frankl, 1992).

Bireysel ve toplulukçu kültürdeki aile yapılarını karşılaştıran Kağıtçıbaşı (2000), toplulukçu kültürlere ait aile modelinde çocuk ailenin gelecekteki güvencesi olarak düşünüldüğünden, çocuğa karşılıklı bağımlılık değerleri yüklendiğini ve onlara maddi ve duygusal yatırım yapıldığını ifade etmiştir. Çocuklar bağımsızlığa, keşfetmeye, yaratıcılığa ve kendine güvenmeye vurgu yapılarak yetiştirilir. Hortaçsu'a (1991) göre batı toplumlarında kişiler kendileriyle ilgili konuşurken "Ben nazik biriyim” derken; Çin, Güney Afrika, Türkiye gibi toplulukçu toplumlarda “Ailem benim nazik biri olduğumu düşünüyor” derler. Bu yüzden, ihtiyaçlar aynı olduğu halde, insanların bu ihtiyaçları karşılama biçimleri kültürden kültüre farklılık göstermektedir. Dolayısıyla Türk kültüründe çocukların küçük yaşlardan itibaren daha bağımlı yetiştirildiği ve karar verme sürecinde aileye ve topluma daha bağımlı olduğu söylenebilir. Anlam arayışı gerilim yaratan bir durum olabilir ve bu doğaldır. Kendisine sunulan yaşam içerisinde insanlar anlam aramak yerine sunulan anlamları yaşarlar. Bu durum hem özgürlüğü hem de özgürlükten dolayı alınacak sorumlulukları kısıtlar. Logoterapiye göre sağlıklı ve uyumlu insan uygun anlam arayışı içerisindedir. Uygun anlam arayışı çabasının, Türk toplumunun yönlendirici ve bağımlılığı özendiren özelliklerinden dolayı da engellendiği söylenebilir.

\section{Varoluşsal Boşluk}

Varoluşsal boşluk, endüstrileşmenin, geleneksel değer kayıplarının sonucu olarak 21. yüzyılın yaygın bir olgusudur (Wong, 2002). Bunun nedeni, insanın yaşadığı iki yönlü kayıp olabilir. nsanlık tarihinin başında insan hayvanca içgüdülerini kaybetmiştir. nsan seçim yapmak zorundadır fakat buna ek olarak, insan davranışlarını yönlendiren geleneklerin hızla azaldığı son gelişme döneminde bir başka kayıpla daha yüz yüze gelmiştir. Hiçbir içgüdü bireye yapacağını söylemez, bazen birey neyi arzuladığını bile bilmez. Bunun yerine kişi ya diğer 
insanların yaptığı şeyleri arzular (uydumculuk), ya da diğer insanların kendisinden yapmasını istediği şeyleri yapar (totalitercilik) (Jones, 1995).

Varoluşsal boşluk genel anlamsızlık ve boşluk duygularını ve can sıkıntısını kapsar (Wong, 2002). Köyden kente göç, hızlı endüstrileşme, teknolojik gelişme, işbölümünün artması, işsizlik giderek insanları psikolojik bunalıma sürüklemektedir. Bireyler kendilerini kalabalıklar içerisinde yalnız hissetmektedirler (Voltan-Acar, 2004/2012 s.102-103). Örneğin, "Pazar günü nevrozunu", yoğun bir haftadan sonra yaşanabilecek boşluğu da içerdiğinden tatil depresyonuna örnek verilebilir. Birçok intihar olayı bu varoluşsal boşluğa (vakuma) bağlanabilir. Depresyon, saldırganlık, uyuşturucu v.b alışkanlığı gibi bu türden yaygın olaylar ve bunların altında yatan varoluşsal boşluk kavranmadığı sürece anlaşılmaz. Bu ayrıca emekli ve yaşlı insanların yaşadığı krizler için de geçerlidir (Frankı, 1992).

Varoluşsal boşluk durumunu yaşayan birey, hayatındaki bütün anlamı kaybettiğini hisseder. Bu varoluşsal boşluk durumu devam ederse bireyde Frankl'ın noölojik nevroz olarak adlandırdığı hastalık söz konusu olabilir. Frankl noöjenik nevrozların psikonevrotik semptomlarla birleştirilerek, varoluşsal nevrozun psikolojik hastalıkların altında bir hastalık olarak kabul edilebileceğini söylemiştir. Aynı zamanda Frankl, varoluşsal nevrozun ruhsal hastalık olmadığını ve manevi bir stres olduğunu vurgulamıştır; fakat bu durum devam ederse, bu boşluk noölojik nevrozlara ve psikonevrotik durumlara yol açabilir (Das, 1998).

Modernleşme kuramına göre, 'geçiş' toplumlarında, geleneksel toplumsal ilişki ve biçimlerle Batı'dan ithal edilenler arasında uzlaşmaz bir çelişki yaşanmakta; gelenekselmodern 'ikililiği'nin devam ettiği bu toplumlarda, geleneksel değerler ve kurumlar modernleşmeye direnmekte ve engel teşkil etmektedir (Özbek, 1991). 60’lı yıllarda sanayileşmenin yaygınlaşması, irili ufaklı yerleşme merkezlerine karayolları ile bağlantılar kurulması bu yollar üzerinde hem ticaret, hem insan geliş-gidişlerini yoğunlaştırmıştır. Özellikle bu yıllardan sonra köyden kente göç büyük bir ivme kazanmıştır. Dolayısıyla bu bölgelerde yaşayan kentteki köylüler toplumsal yaşam ve kültür açısından bir boşluk yaşamaya başladılar (Ercins, 2009). Bunun dışında yabancılaşma ve giderek yalnızlaşma da yaşanan problemler arasında sayılabilir. Geleneklerden kopmak ya da kopmamak arasında kalan insanlar varoluşsal boşluk yaşayabilirler. Geçmişte daha geniş ailelerin yaşandığı toplum, giderek kendini çekirdek aile yapısına bırakmıştır. Dolayısıyla bireyselleşme süreci, geleneklerden ve kültürden kopma çabaları hazır olmayan Türk toplumunda "varoluşsal boşluk" olarak tanımlanabilecek sorunları da beraberinde getirebilir. 


\section{Yaşamın Anlamı}

Yaşamın anlamı insandan insana, günden güne, saatten saate farklılık gösterir. Bu nedenle önemli olan genelde yaşamın anlamı değil, daha çok belli bir anda bir insanın yaşamının özel anlamıdır (Patterson, 1973). Herkesin yaşamında özel bir mesleği veya uğruna çaba harcanacak bir amacı, yerine getirilmeyi bekleyen somut bir görevi vardır. Bu nedenle herkesin işi, bunu yürütmeye yönelik özel fırsatları kadar eşsizdir (Nystul, 1999). Gould'e (1993) göre Frankl'ın toplama kampındaki deneyimleri yaşamın anlamlılığını takdir etmesini artırmıştır. Frankl ölümü bir tehdit olarak değil bireylerin hayatlarını dolu dolu yaşamaları için bir teşvik olarak görmüştür. Dolayısıyla ölüm farkındalığı bireyin korku ve dehşet yaşamasından çok yaratıcılığını ve yaşama sevincini artırabilir (Akt; Sharf, 2014 ss.145).

Anlam arayışı ya da anlam bulma çabası her insan için özel ve farklıdır. Anlam arayışı içerisinde olmak aynı zamanda yaratıcı ve aktif düşünme becerilerini de gerektirir. Özellikle uygun anlamın bulunması ve sorumluluğun alınması noktasında bu beceriler önemlidir. Çocuk yetiştirme biçimlerine bakıldığında, koruyuculuk, Türk toplumunda önem kazanmaktadır. Aşırı koruyuculuk, çocukların sorumluluk almaması gibi bir durumla sonuçlanmıştır. Ayrıca, destek, hep ana-baba, büyüklerden geldiği için, gençlerin olgunlaşması gecikebilir (Voltan-Acar 2004/2012 ss.102-104). Dolayısıyla, Türk toplumundaki gerek çocuk yetiştirme biçimlerinin, gerek eğitim sisteminin bireylerin yaratıcı ve aktif düşünmeleri yerine yönlendirilmelerine neden olduğu söylenebilir.

Bunun yanında ataerkil toplum özelliklerinin etkisiyle de özellikle bazı ailelerde hala erkeğin sözü geçmektedir. Toplumsal cinsiyet açısından hala sıkıntılar yaşandığı söylenebilir. Anlam arama çabası sorumluluğu ve gerilimi beraberinde getirdiğinden yorucu bir süreç olabilir, fakat bu süreç ruh sağlığı açısından önemlidir. Türk toplumunun toplulukçu ve koruyucu özellikleri göz önüne alınırsa, bireylerin kendilerine özgü yaşam anlamlarını tam anlamiyla belirledikleri söylenemez.

\section{Varoluşun Özü}

Yaşamın anlamı her zaman değişir ancak hiçbir zaman yok olmaz. Logoterapiye göre birey yaşam anlamını üç farklı yoldan keşfedebilir. Bunlar; bir eser yaratarak ya da bir iş yaparak, bir şey yaşayarak ya da bir insanla etkileşerek, kaçınılmaz acıya yönelik bir tavır geliştirerek olur. Bunlardan ilki yani başarı yolu oldukça açıktır (Frankl, 1992). Frankl yaratıcılığı insanı çağıran ve herkesin gerçekleştirmek için tek başına olduğu yaratıcı bir çalışma veya sanat ve bilgince çaba olarak tanımlanmıştır (Yalom, 2000). Yaşamda anlam bulmanın ikinci yolu ise iyilik 
doğruluk güzellik gibi bir şeyi yaşamak, doğayı ve kültürü yaşamak, son ve bir o kadar önemlisi de olanca eşsizliğiyle bir insanı yaşamaktır. Bir başka deyişle, onu sevmektir(Wong, 2002).

Türk aile yapısında çocukların yeri önemlidir. Aileler çocukları olduktan sonra yaşamlarını çocukları için yeniden düzenlerler. Bir anlamda çocukları için yaşarlar. Çocuğu kaç yaşında olursa olsun aile çocuğunun geleceğinden kendisini sorumlu hisseder. Benzer şekilde aile üyelerinin birbirinden tamamen bağımsız olmadıkları da söylenebilir (Tezcan, 1991 ss.34). Dolayısıyla Türk kültüründe çocuklar ya da aile üyeleri bir süre sonra anne ve babanın yaşam anlamı haline gelebilir.

Toplumcu ve ataerkil kültür yapısından dolayı kadınlar sadece çocuk doğurmak anlamında üretken sayılırlar, fakat son yıllardaki modernleşme çabalarıyla da beraber artık Türk kadınları iş alanlarında da üretken olabilmektedir (Doğan, 1993 ss.87-90). Kadının toplumdaki rolünün artmasıyla beraber, Türk kadını açısından farklı yaşam amaçlarının ortaya çıktığı söylenebilir. Türk toplumunda bir işle meşgul olmanın, çocuk yetiştirmenin ve yaratıcı eserlerin ortaya konmasının önemli olduğu söylenebilir. Ayrıca son yıllarda kadının toplumdaki rolünün artması da yaşamdaki amaçların artması açısından önemli bir gelişme olarak ifade edilebilir.

\section{Sevginin Anlamı}

Bir başka insanı kişiliğinin en derindeki çekirdeğinden kavramanın tek yolu sevgidir. Hiçbir kimse sevmediği sürece bir başka insanın özünün tam olarak farkına varamaz. Sevgisi yoluyla insan, sevilen kişideki temel kişilik özelliklerini ve eğilimlerini görebilecek duruma gelir ve buna ek olarak gerçekleşmemiş olan ve ancak gerçekleştirilmesi gereken potansiyelleri görür. Kişi, sevdiği insanın ne olabileceğinin ve ne olması gerektiğinin farkına varmasını sağlayarak potansiyellerini gerçekleştirmesini sağlar (Frankl, 1992).

Sevmek, sevilmek Türk toplumu için önemli kavramlardır. Edebiyat tarihine bakıldığında da sevginin önemi görülebilir. Leyla ile Mecnun, Ferhat ile Şirin gibi yapıtlar Türk toplumunda önemli yeri olan ve sevgiyi vurgulayan eserlerdir (Pala, 2000). Toplumcu kültür özelliklerinden dolayı Türk aile yapısında saygı, birlik, beraberlik ve sevgi önemli kavramlardır. Bu kavramlar çocuğun yetiştirilmesinde de çok sık vurgulanır. Türk ailesinde bağlılık önemlidir (Hortaçsu, 1991). Ayrıca slam dininde insan ve Allah sevgisi çok sık vurgulanır. "Yaratılanı severiz, yaratandan ötürü" sözüyle tanınan ünlü Türk halk şairi Yunus Emre, Allah sevgisini ve tasavvufi açıdan insan sevgisini de vurgular. Dolayısıyla Türk toplumunda slam dininin etkisinden dolayı bir insanı sevmek ve bu sevgi uğruna emek harcamak önemlidir. Türk kültürü için toplulukçu kültür özelliğinden ve slam dininin etkisinden dolayı "sevginin anlamı” nın uygun bir kavram olduğu söylenebilir. 


\section{Acının Anlamı}

Yaşamda bir anlam bulmanın üçüncü yolu, acı çekmektir. Umutsuz bir durumla karşılaşıldı ğında, değiştirilemeyecek bir kaderle yüz yüze gelindiğinde bile yaşamda bir anlam bulunabilir; çünkü o zaman önemli olan, kişisel bir trajediyi bir zafere dönüştürmektir. Kendi zor durumunu bir başarıya dönüştürmek sadece insana özgü bir potansiyeldir. Durumu değiştiremeyecek bir noktaya gelindiğinde -örneğin iyileşme şansı olmayan bir hastalık gibiinsan kendini değiştirme yoluna gider (Frankl, 1992).

Frankl gibi varoluşçu düşünürler insanların anlam ihtiyaçlarının veya arayışlarının onlara daha çok sıkıntı verdiği görüşündedirler. Anlam arayışının ve isteminin insanların hayatlarında karşılaştıkları acı verici olayların neden olduğu stresi hafiflettiği belirtilmiştir. Özellikle travmatik olaylarda anlam arama yeteneği, bu olaylara uyum sağlama yeteneğini artırır (Greenstein, 2000). Acı anlam arayışı için gerekli değildir fakat anlamın sorgulanmasında bir tetikleyicidir. nsanların zor durumlarda hayatta kalması uygun anlamlar bulabilmesine de bağlıdır. Anlamsız bir şekilde çekilen acı ümitsizliği de beraberinde getirir. Logoterapistler acının nedeniyle ilgilenmezler fakat danışanların acı durumlarında doğru davranışları seçmelerine yardımcı olurlar (Wong, 2002).

Batı toplumlarının aksine doğu toplumlarında kendi duygularını ifade etmeye odaklanmaktan ziyade diğerlerinin duygularına duyarlı olmak daha önemlidir. Bu nedenle bu toplumların üyeleri duygu ifadelerini kontrol etmeyi öğrenerek sosyalleşmektedir (Sargut, 2001). Dolayısıyla doğu toplumlarında insanlar acı veren olaylar karşısında daha duyarlı olmaya çabalar ve karşısındakini anlamaya çalışır. Başka bir deyişle, acının anlamının Türk toplumunda farklı bir anlam kazandı̆̆ı söylenebilir.

Beeley (1983) 1950'lerde Türkiye' de politikanın demokratikleşmesiyle beraber geniş bir dış borç programı uygulanmaya başlayınca, büyük kentlerdeki sanayi akımının kırsal kesimden göçü hızlandırdığını ifade etmiştir. ç göçler ile şehirlerin çevresindeki gecekonduları doldurmayı sürdüren insanlar, biraz da yalnızlıktan kurtulmak amacıyla kendi hemşerilerinden oluşan mahalleler meydana getirmiştir. Bu mahalleler birer gecekondu yaşamı sergilerken, diğer taraftan o dönemin kentlileşmeye çalışan ve kendi içinde bocalayan insanlarından oluşmuştur.

Türk kültürü açısından önemli bir yeri olan arabesk müziklerdeki duygusal ögelere bakıldığında çoğunlukla aşk, ayrılık, ölüm, aldatma, özlem, cinayet gibi ögelerin işlendiği görülmektedir. Özellikle bir dönemin popüler müziği olan arabesk müzik Türk insanı için önemli olmuştur. Özellikle kent yaşamının acımasızlı̆̆ı karşısında bir bakıma sindirilmiş, korkutulmuş, dışlanmış bu kitlenin kültürü de elbette yoksulluğun nedenlerini kaderde arayan, 
mutluluğa ancak çile ve acıyla ulaşılacağını sanan, kurtuluşu Tanrı'nın yardımıyla mümkün olmayan hedeflerde gören bir biçimde olacaktır (Erşanlı, 2012). Dolayısıyla Türk insanı için “acı” farklı bir anlam taşıdı̆̆ı söylenebilir.

Türk toplumunun büyük bir kısmının slami görüşle yetiştirilmesi, kadere, alın yazısına, iyi ya da kötü her şeyin Allah'tan geldiğine inanılması; kişilerin sorumluluk almasını, değişimin kendi ellerinde olduğu gerçeğini kavramalarını zorlaştırmaktadır (Voltan-Acar, 2004/2012 ss.102-104). Dolayısıyla toplumda kaderci bakış açısının yaygın olduğu söylenebilir. Kaderci toplumlarda olacaklar için önceden önlem almak, ileriye yönelik planlar yapmak ve bir şeyi başarmak için gereğinden fazla zorlamak gereksiz görülebilmektedir (Aycan ve Kanıngo, 2000) Bu bakış açısıyla Türk toplumu slam dininin de etkisiyle yaşadığı acı olayları kadere bağlama eğilimindedir. Ayrıca tasavvuf inancında acı çekmek ve çilehaneler oldukça önemlidir. Dolayısıyla, “acının anlamının” dini bakış açısından dolayı Türk toplumu için anlamlı olduğu söylenebilir.

\section{Süper Anlam}

Nihai anlam zorunluluk gereği insanın sınırlı zihinsel yetisini aşar. Logoterapide bu bağlamda bir süper anlamdan söz edilmektedir. nsandan istenen şey, bazı varoluşçu felsefecilerin savunduğu gibi yaşamın anlamsızlığına katlanmak değil, yaşamın koşulsuz anlamlılığını ussal terimlerle kavrama yetkisinden yoksun oluşuna dayanmaktır. Logos (anlam), mantıktan daha derindir (Frankl, 1992). Frankl yazılarında ruh, maneviyat ve din arasındaki benzerlik ve farklılıkları da vurgulamıştır. Manevilik insanın anlam arayışında da ortaya çıkmıştır. Din nihai anlamı içermektedir. Frankl dinin önemi üzerinde de durmuştur ve dini derin maneviyatla eşit tutmuştur (Wong, 2002).

Süper anlam kavramında dini, ilahi bakış açısından söz edilmektedir. Geleneksel Türk kültüründe dini bakış açısının çok önemli ve yaygın olduğu bilinmektedir. Özellikle slam dininde ilahi Tanrı bilinci oldukça etkilidir. Türk toplumunda çocuk yetiştirme biçimlerinde dinin etkisi de önemlidir (Hortaçsu, 1991). Bunun yanında slam dininin etkisiyle de toplumumuzda manevi boyutun önemi yadsınamaz. Dolayısıyla anlam arayışında Türk toplumu açısından süper anlamdan söz edilebilir. Mevlana'nın "Ne olursan ol gel” şeklindeki söylemlerinde koşulsuz kabulün üzerinde durulmuştur. Mevlana ve Hacı Bektaşi Veli gibi düşünürler öğretilerinde Allah ve insan sevgisini çok sık vurgulamışlardır. Ayrıca slam dinindeki koşulsuz teslimiyet bu öğretilerde açıkça görülmektedir. Türk insanının bu ünlü düşünürlerden etkilenerek, ilahi anlam arayışlarına girdiklerini söylemek mümkündür. slam dininin etkisinden dolayı Türk toplumu için süper anlam kavramının yaygın olduğu söylenebilir. 


\section{Yaşamın Çekiciliği}

nsan yaşamını anlamdan yoksun bırakıyor gibi görünen şeyler sadece acıyı değil, ölümü de kapsamaktadır. nsan varoluşunun geçici olması, bunu kesinlikle anlamsız kılmaz, ama insanın sorumluluklarını oluşturur; çünkü her şey, insanın öz itibarıyla geçici olan olasılıkları gerçekleştirmesine bağlıdır. nsanın, her an, şöyle ya da böyle, varoluşunun anlamının ne olacağına karar vermesi gerekir (Frankl, 1992).

nsan varoluşunun temelde geçici oluşunu aklında tutan logoterapi, kötümser değil, daha çok eylemcidir. Bu nokta benzeştirmeli olarak dile getirilecek olursa; karamsar kişi, her gün bir sayfasını kopardığı duvar takviminin geçen her günle biraz daha inceldiğini korku ve hüzünle gözleyen bir insana benzer. Öte yandan yaşamındaki sorunları anlamlı şekilde kabullenen insan, her gün takviminden bir yaprak koparan, ancak bunları arkalarına birkaç günlük notu aldıktan sonra öncekilerle birlikte düzenli ve özenli bir şekilde dosyalayıp saklayan bir insana benzer (Yalom, 2000).

Frankl varoluşun geçici olmasının yaşamın anlamını azaltmadığını belirtmiştir. Bu noktada logoterapide dini bakış açısının etkileri olduğu söylenebilir. Türk kültüründe ölüm konusunda çok fazla araştırma yapılmamıştır. Psikolojik açıdan ölüm konusunda ilk çalışma Ünver (1938) yılında yapılmıştır. Ölüme ilişkin tutumların çalışıldı̆̆ı bu araştırmada Türk kültüründe ölümden korkulmadığı, Türklerin ölümü tevekkül ile karşıladığı belirtilmiştir (Akt; Sezer ve Saya, 2009). Diğer kültürlerde olduğu gibi Türk kültüründe de yaşamın uzunluğu değil, nasıl geçirildiği önemlidir.

\section{Logoterapide Kullanılan Teknikler}

Paradoksal niyet ve düşünce odağını değiştirme, logoterapi çerçevesinde geliştirilen iki tekniktir. Logoterapi genellikle ya hümanistik psikoloji kategorisinde ya da fenomenolojik veya varoluşçu psikiyatriyle özdeşleştirilir.

\section{Paradoksal Niyet Tekniği}

Paradoksal niyet tekniğini Frankl 1929'dan beri kullanmıştır, ancak bu tekniğin resmi tanımını 1939'da yayınlamıştır. Daha sonra bu teknik geliştirilerek bir metodolojiye dönüştürülmüş ve logoterapi sistemiyle bütünleştirilmiştir (Nystul, 1999). Belli bir semptom, danışanda, tekrar ortaya çıkabileceği konusunda korkulu bir beklenti yaratır. Ancak korku, her zaman için tam da korkulan şeyi yaratma eğilimindedir ve bu nedenle beklenti kaygısı, danışanın olmasından korktuğu şeyi tetikleme eğilimi gösterir, bu şekilde kendini sürdüren bir kısır döngü oluşur: Bir semptom bir fobiyi uyandırır; karşılık olarak fobi semptomu kamçılar ve semptomun yeniden ortaya çıkması fobiyi pekiştirir. Korkunun bir nesnesi de korkunun kendisidir. Danışanlar sık sık "kaygı konusundaki kaygıdan” söz ederler. Yakından incelenince bu "korku korkusunun" 
birçok durumda danışanın kaygı nöbetlerinin potansiyel sonuçları konusundaki tedirginliğinden kaynaklandığı ortaya çıkar. Danışan bu kaygılar nedeniyle düşmekten, bayılmaktan, kalp krizi geçirmekten korkar, fakat bu korku korkusu korkuyu arttırır. "Korku korkusuna” yönelik en tipik tepki, "korkudan kaçmaktır". Danışan kaygısını alevlendiren durumlardan kaçınmaya başlar. Kaygı nevrozlarının başlangıç noktası budur. "Fobiler kısmen kaygının yükseldiği durumlardan kaçma çabasından” kaynaklanır. Kişinin korkmaya başladığı ortamla yüz yüze getirilmesi fobinin gelişmesini önleyebilir (Frankl 1999).

Fobik olaylarda danışan "korku korkusu" sergilemesine karşılık saplantılı-zorlanımlı nevrotik birey "kendinden korkar", bir başka deyimle, intihar edebileceği hatta cinayet işleyebileceği düşüncesine saplanmıştır, ya da kafasındaki garip düşüncelerin, varolan bir psikozun işaretleri olmasından korkar. "Korkudan kaçış”ın fobik yapının tipik bir özelliği olmasına karşılık, saplantılı-zorlanımlı danışanın tipik özelliği “saplantılarına ve zorlanımlarına karşı mücadele etmesidir. Ne var ki, ne kadar çok mücadele ederse, bu saplantı veya zorlanımlar da o kadar güçlenir. Baskı, karşı baskı yaratır ve bu karşı baskı da dönüp baskıyı artırır. Burada da bir kısır döngü söz konusudur (Wong, 2002).

Paradoksal niyet fobik olan danışanlarda, danışanı, korktuğu şeyi yapmaya veya saplantıl1-zorlanımlı danışanlarda, danışanı korktuğu şeyin olmasını arzulamaya özendiren bir süreç olarak tanımlanabilir. Böylece fobik danışanın, korkularından kaçmasına, saplantılızorlanımlı danışanın da saplantılarına ve zorlanımlarına karşı mücadele etmesine bir son vermesi sağlanır. Bir açıdan patojenik (hastalık yaratan) korkunun yerini paradoksal (çelişkili) bir arzu alır. Böylece beklenti kaygısının kısır döngüsü kırılmış olur (Frankl, 1999). Örneğin kişi sürekli ellerini yıkar çünkü, enfeksiyon kapmaktan korkar. Bu durumdaki danışanın kendi kendine “yeteri kadar mikroplarım yok, daha çok kirlenmeliyim” demesi sağlanır (Wong, 2002).

Anne baba tutumlarından dolayı güvensiz olarak yetiştirilen bireylerde başarısızlık korkusunun da yaygın olduğu söylenebilir (Kağıtçıbaşı, 1991). Özellikle kendine güvensizlik ve kendini ifade edememe konusunda yaşanan sorunların da etkisiyle yaşanan problemlerin çözümünde paradoksal niyet yöntemi etkili olabilir. Her zaman en iyisini yapmak konusunda koşullandırılan Türk insanı özellikle sosyal fobilerin tedavisinde bu tekniği uygulamakta güçlük yaşayabilir. Dolayısıyla danışanlara bu teknik uygulanmadan önce iyi bir açıklamada bulunması gerekebilir. Psikolojik danışmanın danışanı iyi tanıması ve paradoksal tekniğin başarıyla sonuçlanması için iyi yönlendirmesi önemlidir.

Türk kültüründe genel anlamda anne-babaların çocuklarından olduklarından daha iyi performans bekledikleri söylenebilir. Bu durum çocuklar ve gençler için kaygı yaratabilir. Dolayısıyla paradoksal niyet tekniğinin mükemmeli oynama ve isteme sürecini kırması 
özellikle ergenlerde etkili olabilir ancak tekniğin başarıyla sonuçlanması için iyi bir yapılandırma önemlidir.

\section{Düşünce Odağını Değiştirme (Düşünmeme) Tekniği}

Danışanın mücadelesiyle ayırt edilen cinsel nevrotik yapı logoterapinin üzerinde durduğu önemli problemlerden birisidir. Ancak burada danışan, bir şeye karşı değil, cinsel haz için mücadele eder; ama hazzın, ne kadar amaçlanırsa o kadar elden kaçırılacağı, logoterapinin temel ilkelerinden birisidir (Frankl, 1992). Cinsel güç ve orgazm niyetin hedefi olduğu anda, dikkatin de hedefi olur. Logoterapide bu terimlere "hiper (aşırı) niyet" ve "hiper düşünme" denmiştir. Bu iki kavram birbirini pekiştirir, dolayısıyla bir geribildirim (feedback) mekanizması oluşur. Danışan, gücünü garantilemek için, kendine, kendi performansına ve deneyimine dikkat eder. Aynı ölçüde, dikkat eşten ve onu cinsel açıdan uyarabilecek uyarımlar anlamında eşin sunduklarından uzaklaşır. Sonuç olarak cinsel güç gerçekte azalır. Bu da karşılık olarak danışanın hiper niyetini artırır ve böylece bir kısır döngü tamamlanmış olur. Bu döngüyü kırmak için merkezkaç kuvvetlerin uygulanması gerekir. Danışan, güç aramak yerine, kendisi olmalı, kendini vermelidir. Ayrıca danışan kendini gözlemek yerine kendini unutmalıdır. Bu işlemi uygulamak, başka bir deyişle danışanın hiper düşünmesine karşı harekete geçmek için düşünce odağını değiştirme tekniği geliştirilmiştir (Frankl, 1999).

Türk toplumunda cinsel yönden başarıya çok ağırlık verildiği ve cinsel organın başarı aracı olarak kullanıldığı söylenebilir. Bu tür ağır başarı beklentileri endişe ve korkulara neden olabilir. Korkunun, endişenin olduğu yerde cinsel uyum olmaz (Öztürk, 1997). Dolayısıyla, Türk toplumunda cinselliğin uygun olmayan biçimde yaşandığı ve cinsel nevrotik yapının yaygın olduğu söylenebilir. Dolayısıyla hem bakış açısının değiştirilmesinde hem de uygun cinsel yaşantıların artırılmasında düşünce odağını değiştirme tekniği etkili olabilir. Frankl, ilke olarak, danışanlarının bakışlarını kendilerinden, sıkıntılarından, nevroz kaynaklarından uzağa, kişiliklerinin bütün olan parçalarına ve dünyada kendileri için uygun olan anlamlara çevirmek olan "düşünce odağını değiştirme" (dereflection) tekniğini geliştirmiştir. Düşünce odağını değiştirme ya da düşünmeme tekniği çok basittir ve danışana kendisi üzerinde odaklanmasından çok kendisi dışında bir anlam araması sağlanır (Yalom, 2000).

Yukarıdaki açıklamalar dikkate alınırsa Türk kültüründeki bireylerin günlük hayatın sıkıntılarıyla çok fazla zaman harcadığı söylenebilir. Günlük işlerin yoğunluğunun dışına çıkıldığında ise bireyler kendine, kendi sıkıntılarına odaklanabilirler. Zamanının çoğunu kendine odaklanmakla geçiren bireylerin farklı anlamlar araması için yönlendirilmesi sıkıntıların artmasını engelleyebilir. Bu açıdan düşünmeme tekniğinin Türk insanı için iyi bir yapılandırmayla başarılı sonuçlar vereceği söylenebilir. 


\section{Sonuç ve Öneriler}

Logoterapideki kavramlara bakıldığında özellikle anlam istemi, varoluşsal engellenme, varoluşsal boşluk, yaşamın anlamı, varoluşun özü, sevginin anlamı, acının anlamı, süper anlam, yaşamın çekiciliği gibi kavramların Türk kültürü açısından da anlamlı kavramlar olduğu söylenebilir. Bununla birlikte logoterapide ifade edilen paradoksal niyet ve düşünce odağını değiştirme olmak üzere iki teknikten bahsedilmiştir. $\mathrm{Bu}$ iki tekniğin iyi bir yapılama ile Türk kültüründe kullanılabileceği düşünülmektedir.

Kültürün çeşitli tanımları olmakla birlikte kültür için "geleneksel fikirler ve bunlara bağlı değerler”, “öğrenilmiş davranışların bir bütün olarak nesilden nesile aktarılması”, "paylaşılan semboller ve anlamlar", "bir grubun davranışlarında önceden tahmin edilebilir ve belirli farklılıklara yol açan deneyimler" ve "davranışları bir sisteme oturtan fikir, uygulama, norm ve anlamlar bütünü” gibi tanımlar ileri sürülmüştür (Kağıtçıbaşı, 2000). Türk Kültürü’nün özellikleri olarak; kadercilik, kanaatkarlık, pek girişken ve çalışkan olunmaması ve yeni koşullara uyma esnekliğinde zayıflık gösterme özellikleri sıralanmaktadır. Hâlbuki bireyci kültürün özellikleri ise, keşfedebilme, anlam çabası, çalışkanlık, belirsizlikten korkmama ve yüksek öğrenme tutkusu olarak ortaya çıkmaktadır. Bireyci kültürün özellikleri ile Türk kültürünün özellikleri karşılaştırıldığında Türk kültürünün bireyci kültür olmadığı açıkça görülmektedir (Ergun, 1991).

Logoterapi insanın anlam arayışı çabası içerisinde olması gerektiğini vurgulamıştır. Anlam arayışının ise gerilimli bir süreç olduğu ve daha çok bireyci kültürrün özelliklerini gerektirdiği söylenebilir. Türk kültürünün ise bölgeden bölgeye, kırsaldan kente, hatta geleneksel aileden çekirdek aileye değisştiği söylenebilir. Dolayısıyla Logoterapinin olduğu gibi -uyarlanmadanTürk kültürüne uygulanması başarısızlığı da getirebilir.

Psikolojik danışma sürecinde psikolojik danışman ve danışanın kültürel geçmişleri de psikolojik danışma sürecinin önemli birer öğeleridir. Psikolojik danışma uygulamalarında danışanın probleminin tanımlanmasında, amaçların belirlenmesinde, müdahale yöntemlerinin seçilip uygulanmasında ve danışan psikolojik danışman ilişkisinde kültürün önemli bir etkisi olduğu söylenebilir. Başka bir deyişle, psikolojik danışman kültürel farklılıklara duyarlı olmazsa danışanın ihtiyaçlarını karşılayamaz. Dolayısıyla logoterapinin kavramlarının ve tekniklerinin uygulanabilmesi için psikolojik danışmanın danışanın hayata bakış açısını, kişiliğini, aile ilişkilerini iyi analiz etmesi önemlidir. Danışan çok iyi tanındıktan sonra, logoterapinin tekniklerinin başarıyla sonuçlanması için iyi bir yapılandırmanın önemli olacağı söylenebilir. 


\section{Kaynakça}

Aycan, Z. ve Kanungo, R.N. (2000) “Toplumsal kültürün kuramsal kültür ve insan kaynaklart uygulamaları üzerine etkileri”. Türkiye'de Yönetimi Liderlik ve nsan Kaynakları Uygulamaları. çinde: Aycan, Z. (ed.) ss:25-53. Türk Psikologlar Derneği Yayınları, Ankara.

Aycan, Z., Kanungo, R.N., Mendonca, M.; Yu, K., Deller, J.; Stahl, G.; Khursid, A. (2000). Impact of culture on human resource management practices: A ten country comparison. Applied Psychology: An International Review, 49 (1),192-220.

Beeley, B.W. (1983). Migration the Turkish case. England: Open University Press.

Bektaş, Y. (2006). Kültüre duyarlı psikolojik danışma yeterlikleri ve psikolojik danışman eğitimindeki yeri. Ege Ĕ̈itim Dergisi. 7(1), 43-59.

Das, A.K. (1998). Frankl and the realm of meaning. Journal of Hümanistic Education and Development. 36 (4), 199-212.

Doğan, . (1993). Sosyoloji. Ankara: maj Yayıncılık.

Doğan, S. (2005, Eylül). 21. yüzyılda psikolojik danışma alanının değişen dünya görüşü. VIII.

Ulusal Psikolojik Danışma ve Rehberlik Kongresi, Marmara Üniversitesi, stanbul

Ercins, G. (2009). Türkiye' de popüler kültür görünümleri ve gençliğe yansımaları. VI. Ulusal Sosyoloji Kongresi Bildiri El Kitabı, Adnan Menderes Üniversitesi, Aydın 489-511.

Erdur-Baker, Ö. (2007). Psikolojik danışma ve kültürel faktörler. Türk Psikolojik Danışma ve Rehberlik Dergisi, 27, 109-122

Ergun, D. (1991). Türk bireyi kuramına giriş: Türk kültürünün özellikleri. stanbul:Gerçek Yayınevi.,

Erkal, M., Baloğlu, B.,ve Baloğlu, F. (1997)., Ansiklopedik sosyoloji sözlüğü. stanbul: Der Yayınları.

Erşanlı, B. (2012). Bir alt kültür yansıması olarak arabesk video müzik klipleri dilinin incelenmesi. Journal of Life Sciences, 1(1),117-123.

Frankl, E. V. (1992). nsanın anlam arayışı.(Çev. S. Budak). Ankara: Öteki Yayınevi..

Frankl, E.V. (1999). Duyulmayan anlam çı̆̆glı̆ Ankara: Öteki Yayınevi 
Gültekin, F. ve Voltan-Acar, N. (2004). Transaksiyonel analizin Türk kültürüne uyarlanabilirliği: Kültür açısından eleştirel bir bakış. Ĕ̆gitim ve Bilim, 133, 28-39.

Greentein, M. (2000). Cancer and the experience of meaning: a group psychoterapy for people with cancer. American Journal of Psychotherapy, 54 (4),486-5001.

Herman, J. L., Buffardi, L., ve Tetrick, L. E. (2006). Cross-cultural self report: Why we should and when we shouldn't. Paper presented in Symposium, Self-report Measurement Issues in Micro-organizational Research, Academy of Management Annual Meeting, Atlanta, GA.

Hortaçsu, N. (1991). nsan ilişkileri. Ankara: mge Kitabevi Yayınları.

Jones, R.N. (1995). The theory and practice of counseling ( $2^{\text {nd }}$ Ed.). London: Cassell..

Kağıtçıbaşı, Ç. (1987). Individualism and collectivism. A universal dimension? In Ç. Kağıtçıbaşı (Eds.). Growth and progress in cross-cultural psychology (pp. 135-200). Lincoln: University of Nebraska Press.

Kağıtçıbaşı, Ç. (1991). nsan aile kültür (2. Baskı). stanbul: Remzi Kitabevi,

Kağıtçıbaşı, Ç. (2000). Kültürel psikoloji kültür bağlamında insan ve aile. stanbul: Evrim Yayıncilık.

Kağnıcı, D.Y. (2013). Çok kültürlü psikolojik danışma eğitiminin rehberlik ve psikolojik danışmanlık lisans programlarına yerleştirilmesi. Türk Psikolojik Danışma ve Rehberlik Dergisi, 5 (40), 222-231.

Kuzgun, Y. (2000). Meslek danışmanlı̆̆ kuramlar ve uygulamalar. Ankara: Nobel Publisher.

Macit, G. (2010). letişim tarzları üzerinde kültürel değerlerin etkisi: Mehmet Akif Ersoy Üniversitesi öğrencileri üzerinde bir araştırma. Yayınlanmamış Yüksek Lisans Tezi, Süleyman Demirel Üniversitesi, Isparta.

Mc. Whirter, J.J. (1983). Cultural factors in guidance and counseling in Turkey: The experience of a fullbright family. Personnal and Guidance Journal, 61, 504-508.

Mocan-Aydın, G. (2000). Western models of counseling and psychotherapy within Turkey:

Crossing cultural boundaries. The Counseling Psychologist, 28, 281-298.

Nystul, S. (1999). Introduction to counseling an art and science perspective. New Mexico State: The Merrill Counseling Series. 
Özbek, M. (1991). Popüler kültür ve Orhan Gencebay arabeski. letişim Yayınları, stanbul.

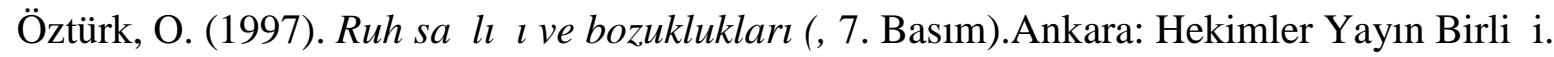
Pala, . (2000). Leyla ile mecnun (2. Baskı). stanbul: Timaş Yayınları.

Patterson, C.H. (1973). The theories of counseling and psychotherapy. New York: Harper Row Publishers.,

Sezer, S. (2012). Yaşamın anlamı konusuna kuramsal ve psikometrik çalışmalar açısından bir bakış. Ankara Üniversitesi Ĕ̈itim Bilimleri Fakültesi Dergisi, 45 (1), 209-227.

Sezer, S. ve Saya, P. (2009) Gelişimsel açıdan ölüm kavramı. Dicle Üniversitesi Ziya Gökalp Eğitim Fakültesi Dergisi, 13, 151-165.

Sharf, R. S. (2014). Varoluşçu terapi (Çev. Ö. Tagay). çinde (Çev. Ed. Voltan-Acar) Psikoterapi ve psikolojik danışma kuramları: ss 143-183. Ankara: Nobel Yayınları. (Reprinted from Theories of psychoterapy and counseling, pp.160-206, by Sharf, R.S, Ed., 2012, Belmont: Brooks Cole Cengage Learning.

Sargut, A .S. (2001). Kültürler arası farklılaşma ve yönetim (2. Baskı). Ankara: mge Kitabevi.Washburn, E.R. (1998). The physician leader as logoterapist. Physician Exe,. 24(4),34-43.

Wong, P. (2002). Logotherapy. Canada: Home Pages

Tezcan, M. (1991). Toplumsal ve kültürel değişme. Ankara: Ankara Üniversitesi Eğitim Bilimleri Fakültesi Yayınları No.164.

Voltan-Acar, N. (2004/2011). Ne kadar farkındayım? Gestalt terapi. 5. Basım, Ankara: Nobel Yayınc1lık.

Yalom, I. (2000). Varoluşçu psikoterapi (Çeviren: Babayiğit). stanbul: Kabalcı Yayınevi. 


\section{Practicality of Logotherapy Concepts and Techniques in Turkish Culture}

According to the existential approach, humans are living beings that can choose among options and that can take responsibility for these decisions. The term, Logotherapy, was first used by existential-oriented Frankl from Vienna during 1920s. Later on, this term was used as a synonym for the term "existential analysis" but in recent years, this term has began to be used as "logotherapy" in a theoretical or therapeutic context in its own theory (Patterson, 1973). The son of a Jewish family, Viktor Frankl, lived in the Auschwitz concentration camp during 19421945. Frankl stated that his life in the concentration camp had effects on logotherapy as well (Jones, 1995).

Logotherapy is a meaning-centered psychotherapy. Logos is a Greek word standing for "meaning" (Jones, 1995). According to Hillmann (2004), logotherapy is a concept based on the idea of understanding the meaning of their existence as the most basic impulse for individuals (Sharf, 2014, pp. 148). Very few clinicians have contributed significantly to the role of the meaning in psychotherapy, and continued their interest in this field. Frankl, on the other hand, focused on the psychopathology and place of the meaning from the beginning of his career (Patterson, 1973).

Together with the lack of researches in the field literature, in Turkey, applicability of theories developed in the West into Turkish culture began to be discussed (Bektaş, 2006; Doğan, 2005; Gültekin and Voltan-Acar, 2004; Kağnıc1, 2013; Voltan-Acar 2004/2012 pp.102110 ,). It can be said that Turkish culture is a collectivist culture in general. While revealing cultural differences or similarities, researchers make use of cultural classifications. One of most commonly used classifications is the individualistic and collectivist culture. It is stated that individualistic culture is predominant generally in Western societies and collectivist culture is predominant in Eastern societies. Evaluations, researches and interpretations conducted by Western researches with individualistic culture perspective may be incorrect (Emmanuel, 1991).

In this study, since focus is especially on the meaning in life, it is considered that examination of concepts and techniques of logotherapy from the point of Turkish culture will be appropriate. As is known, each society bears its own cultural and sociological characteristics. It can be said that there are various differences from the point of traditions, culture and communication among the Turkish communities and Western communities. Therefore, theories of counseling developed in the West may not be suitable for every culture. Analyzing theories developed in the Western societies to improve the field of psychological counseling regarding 
whether they are appropriate for the Turkish culture might prevent any future errors. In this study, primarily information regarding concepts of Logotherapy were given including will to meaning, existential frustration, neogenic neurosis, collective neurosis, neodynamics, existential vacuum, meaning of life, essence of existence, meaning of love, meaning of pain, super meaning and attractiveness of live and paradoxical intention and changing the thought focus. Then, concepts and techniques expressed in the logotherapy were explored in terms of Turkish Culture.

Logotherapy emphasized the need for humans to search for meaning. It can be said that search for meaning is a stressed process and it requires characteristics of the individualistic culture more. In the Turkish culture it can be said to vary from region to region, countryside to city and even from traditional family to nuclear family. Therefore, implementation of Logotherapy into the Turkish culture as it is-without adaptation-may bring along failure.

In the process of psychological counseling, psychological counselor's and client's cultural histories are the important elements. In psychological counseling applications, culture can be said to have a major impact on defining the client's problem, determining the goals, selecting and implementing methods of intervention and in the relationship between psychological counselor and client. In other words, if psychological counselor is not sensitive to cultural differences, they cannot meet client's needs. Following a good knowledge of the client, a good configuration can be important to conclude logotherapy techniques successfully.

As a result, considering concepts in logotherapy, particularly concepts such will to meaning, existential frustration, existential vacuum, meaning of life, essence of existence, meaning of love, meaning of pain, super meaning and attractiveness of live can be said to be significant from the point of Turkish culture. However, in logotherapy, two techniques including paradoxical intention and changing the thought focus are expressed. With a good configuration, these two techniques can be implemented in Turkish culture. 